\title{
An Empirical Study of Taiwan's Real Business Cycle
}

\author{
Kuo-Hsuan Chin $^{1} \&$ Tzu-Yun Huang ${ }^{1}$ \\ ${ }^{1}$ Department of Economics, Feng Chia University, Taichung City, Taiwan \\ Correspondence: Kuo-Hsuan Chin, Department of Economics, Feng Chia University, No. 100, Wenhwa Rd., \\ Seatwen Dist., Taichung City, Taiwan 40724, R.O.C. Tel: 886-989-231-219. E-mail: khchin@fcu.edu.tw
}

Received: December 11, 2017

Accepted: December 28, 2017 Online Published: January 10, 2018

doi:10.5539/ijef.v10n2p124

URL: https://doi.org/10.5539/ijef.v10n2p124

\begin{abstract}
We study the characteristics of the real business cycle and the sources of the economic fluctuation in Taiwan over the last forty years, when it experienced both developing and developed stages of the economy, by considering a small open economy real business cycle model with financial friction. In particular, the breaking time point that distinguishes between developing and developed stages of the economy in Taiwan is chosen on the basis of the International Monetary Fund (IMF). We use a Bayesian approach to obtain the posterior densities for the structural parameters of interest. Conditioning on the Bayesian point estimates, the posterior mean in particular, we generate a set of statistical moments and related statistics that characterize the features and sources of the real business cycle. We find that a real business cycle model with financial friction explains the features of real business cycle in a developing stage of Taiwan's economy well. However, the results it provides are unsatisfactory for matching the characteristics of real business cycle in a developed stage of Taiwan's economy. In addition, the technology shock explains a large fraction of the economic fluctuation, particularly in real output, consumption and investment. More precisely, permanent technology shock explains a larger fraction of the economic fluctuation than a transitory technology shock.
\end{abstract}

Keywords: financial friction, real business cycle, bayesian estimation, permanent technology shock, small open economy

\section{Introduction}

Over the past forty years, Taiwan (Republic of China, R.O.C.) experienced different stages of economic development, transitioning from a developing economy to a developed one. According to "World Economic Outlook", which was reported by the International Monetary Fund (IMF) and published in 1997, Taiwan was identified as a developed country starting in 1998. Aguiar and Gopinath (2007) state several characteristics of the real business cycle in developing and developed countries. Specifically, compared to the real output, the volatilities of consumption and trade balance are relatively large. Moreover, there is a dramatic reverse in the ratio of current account to the real output. (Note 1) By choosing the year 1998 as a breaking point in macroeconomic time series data in Taiwan, we indeed find the characteristics, expected to be occurred in developing and developed economics stated in Aguiar and Gopinath (2007), are shown in pre- and post-sample. Tables 1 and 2 show that the volatilities of consumption and trade balance are larger in the pre-sample than those in the post-sample (Note 2).

In the early 1980s, an important revolution of macroeconomic research, led by an influential paper written by Kydland and Prescott (1982), resulted in the modern development of the theoretical and empirical approaches in macroeconomics. A sophisticated and micro-founded model is constructed with a modern Bayesian estimation approach to explain a country's real business cycle or study the source and the transmission of a country's economic fluctuation. Modern theoretical models, the so-called New Keynesian Dynamic Stochastic General Equilibrium (DSGE) models, and an empirical approach are commonly used in current macroeconomic research. (Note 3) However, still only a small portion of studies depart from a relatively simple DSGE model to explain a country's economic fluctuation. Aguiar and Gopinath (2007) construct a small open economy Real Business Cycle (RBC) model to explain the characteristics of real business cycles in both developing and developed countries, which are represented by Mexico and Canada respectively. They find the model can explain the features of the real business cycles in a developing country well if a permanent technology shock is taken into consideration. Kydland and Zarazaga (2002) argue that a simple real business cycle model can successfully explain "Argentina's Lost Decade" which occurred in the 1980s. García-Cicco, Pancrazi, and Uribe (2010) 
extend the model of Aguiar and Gopinath (2007) by taking both permanent and transitory technology shocks with an international financial friction into account. They find that the estimated model can explain the characteristics of small open developing economies (Argentina and Mexico) very well. However, their results differ from those of Aguiar and Gopinath (2007) in that they state that the permanent technology shock is not a dominant factor explaining the source of the economic fluctuation.

Table 1. Characteristics of real business cycle in Taiwan (1982Q1-1997Q4)

\begin{tabular}{|c|c|c|c|c|c|c|c|c|c|}
\hline \multirow[b]{2}{*}{ Var } & \multicolumn{2}{|c|}{ Standard Deviation } & \multicolumn{5}{|c|}{ Correlation with Output } & \multicolumn{2}{|c|}{ Autocorrelation } \\
\hline & In percent & Relative & -2 & -1 & 0 & 1 & 2 & 1 & 2 \\
\hline $\mathrm{Y}$ & 0.02 & 1.00 & ---- & $-\cdots$ & 1.00 & +--- & ---- & $0.44 * *$ & 0.21 \\
\hline $\mathrm{C}$ & 0.02 & 1.00 & $0.40^{* *}$ & $0.31 *$ & 0.23 & 0.04 & -0.16 & $0.85^{* *}$ & $0.71 * *$ \\
\hline I & 0.09 & 4.5 & $0.39 * *$ & $0.56 * *$ & $0.57 * *$ & 0.15 & 0.16 & $0.50 * *$ & $0.27 *$ \\
\hline TB & 0.05 & 2.5 & $-0.42 * *$ & $-0.42 * *$ & -0.004 & 0.12 & 0.09 & $0.52 * *$ & $0.33 * *$ \\
\hline
\end{tabular}

Note. "Var", "Y", "C", "I", and "TB" are used as abbreviation of "Variable", "Real Output", "Consumption", "Investment", and "Trade Balance" respectively. Quarterly data are seasonally adjusted. "Relative" represents the ratio of the volatility of the variable of interest to the one of output. The cyclical component of the data is extracted via a Hodrick-Prescott filter. "**"indicates that the coefficient is statistically significant at the $5 \%$ level; “**” indicates that the coefficient is statistically significant at the level of $1 \%$.

Table 2. Characteristics of real business cycle in Taiwan (1998Q1-2015Q4)

\begin{tabular}{cccccccccc}
\hline & \multicolumn{3}{c}{ Standard Deviation } & \multicolumn{3}{c}{ Correlation with Output } & \multicolumn{3}{c}{ Autocorrelation } \\
\cline { 2 - 10 } Var & In percent & Relative & -2 & -1 & 0 & 1 & 2 & 1 \\
\hline Y & 0.02 & 1.0 & ---- & --- & 1.00 & ---- & --- & $0.74^{* *}$ & $0.42^{* *}$ \\
C & 0.01 & 0.5 & $0.31^{* *}$ & $0.50^{* *}$ & $0.78^{* *}$ & $0.75^{* *}$ & $0.53^{* *}$ & $0.66^{* *}$ & $0.49^{* *}$ \\
I & 0.10 & 5.0 & $0.39^{* *}$ & $0.72^{* *}$ & $0.77^{* *}$ & $0.61^{* *}$ & $0.44^{* *}$ & $0.67^{* *}$ & $0.44^{* *}$ \\
TB & 0.03 & 1.5 & -0.11 & $-0.24^{*}$ & -0.11 & $-0.23^{*}$ & $-0.31^{* *}$ & $0.45^{* *}$ & $0.29^{*}$ \\
\hline
\end{tabular}

Note. "Var", "Y", "C", "I", and "TB" are used as abbreviation of "Variable", "Real Output", "Consumption", "Investment", and "Trade Balance" respectively. Quarterly data are seasonally adjusted. 'Relative' represents the ratio of the volatility of the variable of interest to the one of output. The cyclical component of the data is extracted via a Hodrick-Prescott filter. "*” indicates that the coefficient is statistically significant at the $5 \%$ level; “**” indicates that the coefficient is statistically significant at the level of $1 \%$.

In this paper, we adopt a small open economy RBC model of García-Cicco, Pancrazi, and Uribe (2010) to study the characteristics of the real business cycle and the source of economic fluctuation in Taiwan when it experienced the stages of developing and developed economy over the past four decades. (Note 4) In particular, not only do we consider both permanent and transitory technology shocks, but we also take international financial friction into account. We use a Bayesian approach to estimate the posterior densities of the parameters of interest, and conduct the statistical inference based on the posterior mean. Compare to related studies, we study the model fit of a simple RBC model explaining the characteristics of the real business cycle in two different economic developments of Taiwan.

The estimated results produce several findings. First, in line with the finding of García-Cicco, Pancrazi, and Uribe (2010), the estimated model can explain the characteristics of Taiwan's real business cycle in the stage of a developing economy. Specifically, the model can capture the larger volatilities of consumption and trade balance, measured as a ratio of the volatility of consumption or trade balance to that of real output. Moreover, the countercyclical feature of the trade balance is also captured by the model. However, the estimated results obtained in the developed economy stage are not satisfactory. Regarding the source of economic fluctuation, both permanent and transitory technology shocks explain a large fraction of the variation in the macroeconomic variables such as real output, consumption and investment under two different stages of Taiwan's economic development.

The remainder of this paper proceeds as follows. Section 2 introduces a micro-founded RBC model. The data source and the basics of the Bayesian approach are introduced in Section 3 with a discussion of the empirical results, and Section 4 concludes.

\section{A Real Business Cycle Model with Financial Friction}

The small open economy model we present here is identical to the model of García-Cicco, Pancrazi, and Uribe (2010). The representative household maximizes the discounted sum of a non-separable utility function as: 


$$
\operatorname{Max} \quad E_{0} \sum_{t=0}^{\infty} v_{t} \beta^{t} \frac{\left[C_{t}-\theta \omega^{-1} X_{t-1} h_{t}^{\omega}\right]^{1-\gamma}-1}{1-\gamma}
$$

where $\beta$ is a discount factor, $\theta$ measures the relative importance between consumption and labor supply, $\omega$ is associated with the elasticity of labor supply, $\gamma$ is measures the curvature of the utility function, $v_{t}$ is an exogenous preference shock to consumption, following a stationary $\operatorname{AR}(1)$ process given by

$$
\ln v_{t+1}=\rho_{v} \ln v_{t}+\varepsilon_{t+1}^{v}, \varepsilon_{t}^{v} \sim \text { i.i.d. } N\left(0, \sigma_{v}^{2}\right)
$$

where $\rho_{v}$ captures the persistence of the shock, and $\varepsilon_{t}^{v}$ is identically, independently and normally distributed with zero mean and standard deviation, $\sigma_{v} . X_{t}$ is an exogenous permanent technology shock, and the logarithm of its first difference is following a stationary AR(1) process given by

$$
g_{t} \equiv \frac{X_{t}}{X_{t-1}}, \ln \left(g_{t+1} / g\right)=\rho_{g} \ln \left(g_{t} / g\right)+\varepsilon_{t+1}^{g}, \varepsilon_{t}^{g} \sim \text { i.i.d. } N\left(0, \sigma_{g}^{2}\right)
$$

where $\rho_{v}$ captures the persistence of the shock, and $\varepsilon_{t}^{g}$ is identically, independently and normally distributed with zero mean and standard deviation, $\sigma_{g}$.

The household chooses the optimal level of consumption, $C$, labor supply, $h$, capital stock, $K$ and nominal deposits, $D$, subject to the following real budget constraint

$$
\frac{D_{t+1}}{1+r_{t}}=D_{t}-Y_{t}+C_{t}+S_{t}+I_{t}+\frac{\phi}{2}\left(\frac{K_{t+1}}{K_{t}}-g\right)^{2} K_{t}
$$

where $r$ is the real rate of holding the domestic bonds, $Y$ is the real output, $g$ is a deterministic growth rate of the permanent technology shock, $S$ is an exogenous domestic spending shock, and the logarithm of the ratio of it to the permanent technology shock is following a stationary AR(1) process given by

$$
s_{t} \equiv \frac{S_{t}}{X_{t-1}}, \ln \left(s_{t+1} / s\right)=\rho_{s} \ln \left(s_{t} / s\right)+\varepsilon_{t+1}^{s}, \quad \varepsilon_{t}^{s} \sim \text { i.i.d. } N\left(0, \sigma_{s}^{2}\right)
$$

where $\rho_{s}$ captures the persistence of the shock, and $\varepsilon_{t}^{s}$ is identically, independently and normally distributed with zero mean and standard deviation, $\sigma_{s}$. The household faces the capital adjustment cost, measured in a quadratic form and $\phi$ measures the degree of the adjustment cost. The capital is accumulated by following the equation:

where $\delta$ is the depreciation rate.

$$
K_{t+1}=(1-\delta) K_{t}+I_{t}
$$

A representative firm produces goods in a perfectly competitive market by using the Cobb-Douglas technology as

$$
Y_{t}=a_{t} K_{t}^{\alpha}\left(X_{t} h_{t}\right)^{1-\alpha}
$$

where $\alpha$ is the capital share of income, $a$ is an exogenously transitory technology shock following a stationary $\mathrm{AR}(1)$ process given by

$$
\ln a_{t+1}=\rho_{a} \ln a_{t}+\varepsilon_{t+1}^{a}, \varepsilon_{t}^{a} \sim \text { i.i.d. } N\left(0, \sigma_{a}^{2}\right)
$$

where $\rho_{a}$ captures the persistence of the shock, and $\varepsilon_{t}^{a}$ is identically, independently and normally distributed with zero mean and standard deviation, $\sigma_{a}$.

The domestic interest rate is assumed to be the sum of the world's rate and the interest rate premium

$$
r_{t}=r^{*}+\psi\left(e^{\frac{\bar{D}_{t+1}-\bar{d}}{X_{t}}}-1\right)+e^{\mu_{t}-1}-1
$$

where $r^{*}$ is the world's interest rate, $\bar{D}$ is the aggregate external debt, $\bar{d}$ is the ratio of trade balance to the real output measured at steady state, and $\psi$ measures the sensitivity of the interest rate premium to the deviation of aggregate external debt and its trend value. (Note 5) $\mu$ is an exogenous interest rate premium shock, and its logarithmic form follows a stationary $\operatorname{AR}(1)$ process given by

$$
\ln \mu_{t+1}=\rho_{\mu} \ln \mu_{t}+\varepsilon_{t+1}^{\mu}, \varepsilon_{t}^{\mu} \sim \text { i.i.d. } N\left(0, \sigma_{\mu}^{2}\right)
$$

where $\rho_{u}$ captures the persistence of the shock, and $\varepsilon_{t}^{\mu}$ is identically, independently and normally distributed with zero mean and standard deviation, $\sigma_{\mu}$ García-Cicco, Pancrazi, and Uribe (2010) neglect a concrete specification of the financial and banking sectors, and take a shortcut by linking the interest rate premium, which 
is defined as the difference between domestic and the world interest rates, to the financial friction. Instead, several current studies follow the approach of Bernanke, Gertler and Gilchrist (1999) by introducing the financial friction into the model via the asymmetric information between lenders and borrowers. Due to the information problem, lenders require a higher interest rate from borrowers than the one occurring in the economy without any financial friction. The interest rate premium stated in equation (9) is similar to the difference between the lending and borrowing rates when the financial friction happens. We follow García-Cicco, Pancrazi, and Uribe (2010) to consider the financial friction in a simple way since we want to study whether a simple model like that can explain the real business cycle characteristics in the different stages of developing and developed economy in Taiwan.

With the model set-up, we can obtain a set of nonlinear equilibrium conditions based on the optimization problems of the household and firm. Then we log-linearize those nonlinear equations around the steady state to obtain a set of linearized equations. Finally, the linear solution techniques such those proposed by Blanchard and Kahn (1980), Klein (2000) and Sims (2002) are used to obtain the model solution. The model solution is also called the policy function or the state equation that characterizes the dynamics of the state variables which is combined with another measurement equation that links the observed data series to the state variables to form a linearized state-space model, igniting the subsequent empirical analysis.

\section{Empirical Data, Approach and Results}

Macroeconomic time series data are downloaded from the database at National Statistics, R.O.C. (Taiwan), from 1982Q1 to 2015Q4. Table 3 shows the source of the data in detail.

Table 3. Source of empirical data

\begin{tabular}{|c|c|c|c|c|}
\hline Variable & Frequency & Unit of Measurement & Note & Covered Range \\
\hline Real GDP & Quarter & Million & & 1982Q1-2015Q4 \\
\hline Consumption & Quarter & Million & & 1982Q1-2015Q4 \\
\hline Fixed Capital & Quarter & Million & & 1982Q1-2015Q4 \\
\hline Trade Balance & Quarter & Million & Export-Import & 1982Q1-2015Q4 \\
\hline
\end{tabular}

Since the time series data include both trend and cyclical components, we first extract the cyclical component of the data series via Hodrick-Prescott filter and then we compute the statistical moments based on them. Those moments computed on the basis of real data series are compared to those calculated in terms of simulated data series, generated from the model solution, to evaluate the fit of the model for explaining the characteristics of the real business cycle in Taiwan.

We estimate the structural parameters of interest via a Bayesian approach. According to Bayes' rule, the posterior density of the parameters is proportional to the multiplication of the likelihood function and the prior density of the parameters. In particular, given the assumption of normality on the error terms in a linearized state space model, the explicit form of the likelihood function can be obtained via the Kalman filter. Regarding the prior density of the parameter of interest, we set uninformative priors for all the parameters to indicate that we rely heavily on the information provided from the data to estimate the parameters. By taking a stationary AR(1) coefficient of the shock as an example, we set it to follow a uniform density, varying between -0.99 and 0.99 . For the standard deviation of the shock, we also set it to follow a uniform density with the lower and upper bounds as 0 and 0.2 , where the value of the upper bound is considered on the basis of the related studies of Taiwan's real business cycle. Table 4 includes the description about the prior mean and standard deviation for the parameters of interest.

After specifying the prior density of the structural parameters of interest, the joint posterior density can be obtained by combining the prior and likelihood function via Markov Chain Monte Carlo (MCMC) simulation techniques. In particular, the sampling algorithm generates candidate draws from a proposal distribution, and those draws, passed by an accept-reject rule, are used to approximate the posterior density and compute the statistical moments of interest afterward. (Note 6 \& Note 7) We present the posterior estimates, the posterior mean in particular, in Table 4. Tables 5 and 6 show the statistical moments of the simulated data and the results of variance decomposition. 
Table 4. Bayesian estimates

\begin{tabular}{|c|c|c|c|c|c|c|c|}
\hline \multirow{3}{*}{ Parameter } & \multirow{2}{*}{\multicolumn{3}{|c|}{ Prior Density }} & \multicolumn{4}{|c|}{ Posterior Density } \\
\hline & & & & \multicolumn{2}{|c|}{ 1982Q1-1997Q4 } & \multicolumn{2}{|c|}{ 1998Q1-2015Q4 } \\
\hline & Distribution & Min. & Max. & Mean & S.D. & Mean & S.D. \\
\hline$g$ & Uniform & 1 & 1.05 & 1.02 & 0.01 & 1.01 & 0.01 \\
\hline$\phi$ & Uniform & 0 & 6 & 5.01 & 1.73 & 5.06 & 1.73 \\
\hline$\psi$ & Uniform & 0 & 5 & 2.83 & 1.44 & 2.81 & 1.44 \\
\hline$\rho_{a}$ & Uniform & -0.99 & 0.99 & 0.49 & 0.57 & 0.55 & 0.57 \\
\hline$\sigma_{a}$ & Uniform & 0 & 0.2 & 0.19 & 0.06 & 0.19 & 0.06 \\
\hline$\rho_{g}$ & Uniform & -0.99 & 0.99 & 0.63 & 0.57 & 0.58 & 0.57 \\
\hline$\sigma_{g}$ & Uniform & 0 & 0.2 & 0.19 & 0.06 & 0.19 & 0.06 \\
\hline$\rho_{v}$ & Uniform & -0.99 & 0.99 & 0.45 & 0.57 & 0.44 & 0.57 \\
\hline$\sigma_{v}$ & Uniform & 0 & 0.5 & 0.08 & 0.14 & 0.05 & 0.14 \\
\hline$\rho_{s}$ & Uniform & -0.99 & 0.99 & 0.56 & 0.57 & 0.53 & 0.57 \\
\hline$\sigma_{s}$ & Uniform & 0 & 0.2 & 0.03 & 0.06 & 0.01 & 0.06 \\
\hline$\rho_{\mu}$ & Uniform & -0.99 & 0.99 & 0.99 & 0.57 & 0.99 & 0.57 \\
\hline$\sigma_{\mu}$ & Uniform & 0 & 0.2 & 0.20 & 0.06 & 0.19 & 0.06 \\
\hline
\end{tabular}

Note. Several parameters are fixed prior to the estimation. According to Teo (2009), we set the elasticity of labor supply and the capital share of income as 0.74 and 0.3 respectively. According to Hwang (2013), we set the discount factor and the capital depreciation rate as 0.99 and 0.025 respectively.

In Table 5, we find that an RBC model with the financial friction explains relatively well the real business cycle characteristics of Taiwan in the stage of the developing economy. In particular, the model can capture the excess volatilities of the consumption and trade balance as well as the countercyclical feature of the trade balance. However, the performance of the model in explaining those characteristics is not satisfactory for the stage of the developed economy in Taiwan.

Table 5. Comparison of statistical moments in simulated and real data

\begin{tabular}{|c|c|c|c|c|}
\hline Descriptive Statistics & $Y$ & $C$ & $I$ & $T B$ \\
\hline \multicolumn{5}{|c|}{ Relative Standard Deviation (vs. Y) } \\
\hline Simulated Result I & --- & 1.13 & 1.64 & 1.71 \\
\hline Simulated Result II & --- & 1.10 & 1.93 & 2.23 \\
\hline Real Data Result I & --- & 1.03 & 4.50 & 2.50 \\
\hline Real Data Result II & --- & 0.59 & 5.00 & 1.50 \\
\hline \multicolumn{5}{|l|}{ Correlation with $Y$} \\
\hline Simulated Result I & --- & 0.99 & 0.85 & -0.02 \\
\hline Simulated Result II & --- & 0.99 & 0.76 & 0.06 \\
\hline Real Data Result I & --- & 0.23 & 0.57 & -0.004 \\
\hline Real Data Result II & --- & 0.78 & 0.77 & -0.11 \\
\hline \multicolumn{5}{|l|}{ Correlation with $T B$} \\
\hline Simulated Result I & -0.02 & -0.01 & -0.35 & --- \\
\hline Simulated Result II & 0.06 & 0.08 & -0.02 & --- \\
\hline Real Data Result I & -0.004 & -0.60 & -0.72 & --- \\
\hline Real Data Result II & -0.11 & -0.34 & -0.65 & --- \\
\hline \multicolumn{5}{|c|}{ First-Order Autocorrelation } \\
\hline Simulated Result I & 0.88 & 0.93 & 0.65 & -0.17 \\
\hline Simulated Result II & 0.81 & 0.87 & 0.28 & -0.27 \\
\hline Real Data Result I & 0.44 & 0.85 & 0.50 & 0.52 \\
\hline Real Data Result II & 0.74 & 0.66 & 0.67 & 0.45 \\
\hline
\end{tabular}

Note. The covered range of the samples in 1982 Q1-1997 Q4 and 1998 Q1-2015 Q4 are represented by the stages of developing (Case I) and developed (Case II) economy respectively. 
In Table 6, the technology shock, emphasized by the RBC model, explains most of the fluctuations in the real output, consumption and investment. Specifically, the permanent technology shock explains a larger fraction of the volatility in both output and consumption. The volatility of trade balance is mainly determined by the interest rate premium shock. The above findings are applied to the stages of developing and developed economy in Taiwan. Compared to related studies, Aguiar and Gopinath (2007) state that the business cycle is the trend in the stage of developing economy in a small open economy since the fluctuations of the main macroeconomic variables are solely determined by the permanent technology shock. However, a different result is found by García-Cicco, Pancrazi, and Uribe (2010), in which the permanent technology shock plays a minor role in explaining the volatility of the variables.

Table 6. Variance decomposition (\%)

\begin{tabular}{ccccc}
\hline Stochastic Shock & $Y$ & $C$ & $I$ & $T B$ \\
\hline & & & 1982Q1-1997Q4 & 21.15 \\
Permanent Technology Shock & 52.23 & 70.32 & 24.35 & 0.47 \\
Temporary Technology Shock & 47.30 & 29.24 & 37.52 & 0.03 \\
Preference Shock & 0.00 & 0.04 & 0.12 & 78.33 \\
Interest Rate Premium Shock & 0.47 & 0.40 & 37.96 & 0.02 \\
Domestic Expenditure Shock & 0.00 & 0.00 & 0.05 & 1.31 \\
\cline { 2 - 5 } & & & $1998 \mathrm{Q} 1-2015 \mathrm{Q}$ & 7.29 \\
Permanent Technology Shock & 56.89 & 74.73 & 19.04 & 0.00 \\
Temporary Technology Shock & 43.02 & 25.14 & 56.92 & 91.40 \\
Preference Shock & 0.00 & 0.00 & 0.01 & 0.00 \\
Interest Rate Premium Shock & 0.09 & 0.13 & 24.03 & 0.00 \\
Domestic Expenditure Shock & 0.00 & 0.00 & & \\
\hline
\end{tabular}

In sum, a simple RBC model with the financial friction still provides a good explanation of the real business cycle characteristics of Taiwan in the stage of developing economy. However, the results obtained over the stage of developed economy in Taiwan are not satisfactory. In addition, the supply shock, which consists of transitory and permanent technology shocks, plays an important role in explaining Taiwan's economic fluctuation over the past forty years.

\section{Conclusion}

In the past decade, only a fraction of studies indicate that the real business cycle features of a small open economy can be characterized in terms of a relatively simple DSGE model. Thus, we adopt an RBC model with the financial friction of García-Cicco, Pancrazi, and Uribe (2010) and divide a full sample into two parts based on the report of the IMF to study Taiwan's real business cycle characteristics and the source of fluctuation in the stages of developing and developed economy.

We find that the model characterizes well Taiwan's real business cycle characteristics in the stage of developing economy. The excess volatility of both consumption and trade balance as well as the countercyclical feature of the trade balance are captured by the model. However, the results obtained over the stage of developed economy are not satisfactory. Thus, the extension of the model setting is probably a good direction for future research. For example, one can take a nominal friction such as the sticky price or wage, monetary or fiscal sector, and a concrete financial sector into consideration. In addition, consideration of both transitory and permanent technology shocks together in model construction is suggested to study whether the business cycle is really the trend in the stage of developed economy.

\section{References}

Aguiar, M., \& Gopinath, G. (2007). Emerging market business cycles: The cycle is the trend. Journal of Political Economy, 115(1), 69-102. http://dx.doi.org/10.1086/511283

An, S., \& Schorfheide, F. (2007). Bayesian analysis of DSGE models. Econometric Reviews, 26(2-4), 113-172. http://dx.doi.org/10.1080/07474930701220071

Bernanke, B. S., Gertler, M., \& Gilchrist, S. (1999). The financial accelerator in a quantitative business cycle framework. Handbook of Macroeconomics, 1, 1341-1393. http://doi.org/10.1016/S1574-0048(99)10034-X

Blanchard, O. J., \& Kahn, C. M. (1980). The solution of linear difference models under rational expectations. 
Econometrica, 48(5), 1305-1311. http://dx.doi.org/10.2307/1912186

Fernández-Villaverde, J. (2010). The econometrics of DSGE models. SERIES: Journal of the Spanish Economic Association, 1(1), 3-49. http://doi.org/10.1007/s13209-009-0014-7

Garcia-Cicco, J., Pancrazi, R., \& Uribe, M. (2010). Real business cycles in emerging countries? American Economic Review, 100(5), 2510-31. http://dx.doi.org/10.1257/aer.100.5.2510

Hwang, Y. N. (2013). An application of the optimal monetary policy in Taiwan: A dynamic stochastic dynamic framework (in Chinese). Central Bank Quarterly, 35(1), 3-33.

Ireland, P. N. (2004). A method for taking models to the data. Journal of Economic Dynamics and Control, 28(6), 1205-1226. http://dx.doi.org/10.1016/S0165-1889(03)00080-0

Klein, P. (2000). Using the generalized Schur form to solve a multivariate linear rational expectations model. Journal of Economic Dynamics and Control, 24(10), 1405-1423. http://dx.doi.org/10.1016/S0165-1

Kydland, F. E., \& Prescott, E. C. (1982). Time to build and aggregate fluctuations. Econometrica, 50(6), 1345-1370. http://dx.doi.org/10.2307/1913386

Kydland, F. E., \& Zarazaga, C. E. (2002). Argentina's lost decade. Review of Economic Dynamics, 5(1), 152-165. http://dx.doi.org/10.1006/redy.2001.0145

Rebelo, S. (2005). Real business cycle models: past, present and future. The Scandinavian Journal of Economics, 107(2), 217-238. http://dx.doi.org/10.1111/j.1467-9442.2005.00405.x

Schmitt-Grohé, S., \& Uribe, M. (2003). Closing small open economy models. Journal of International Economics, 61(1), 163-185. http://dx.doi.org/10.1016/S0022-1996(02)00056-9

Sims, C. A. (2002). Solving linear rational expectations models. Computational Economics, 20(1), 1-20.

Smets, F., \& Wouters, R. (2007). Shocks and frictions in US business cycles: A Bayesian DSGE approach. American Economic Review, 97(3), 586-606. http://dx.doi.org/10.1257/aer.97.3.586

Stock, J. H., \& Watson, M. W. (2005). Understanding changes in international business cycle dynamics. Journal of the European Economic Association, 3(5), 968-1006. http://dx.doi.org/10.1162/1542476054729446

Teo, W. L. (2009). Estimated dynamic stochastic general equilibrium model of the Taiwanese economy. Pacific Economic Review, 14(2), 194-231. http://dx.doi.org/10.1111/j.1468-0106.2009.00447.x

\section{Notes}

Note 1. Stock and Watson (2005) argue that although business cycle volatilities slow down in developed countries, those occurred in emerging or developing economies become unstable with a dramatic reversal to their current accounts, which are so-called "suddenstop" phenomena.

Note 2. The sample period of data is set between 1982 and 2015 with the year 1998 as a break point. Thus, we can balance the number of the data sample in two subperiods. The cyclical components of the data series are extracted via the Hodrick-Prescott nonlinear filter approach.

Note 3. Those sophisticated DSGE models that we refer to here are those constructed with nominal and real rigidities such as sticky price or wage, investment adjustment cost or habit formation on consumption, and the fiscal and monetary policy rules.

Note 4. It differs from García-Cicco, Pancrazi, and Uribe (2010) in that the country we choose to study experienced stages of both developing and developed economy. In addition, we make use of quarterly data on estimation instead of using annual data.

Note 5. According to Schmitt-Grohé and Uribe (2003), equation (9) is set to allow for the unique existence of the steady state in a small open economy RBC model.

Note 6 . We achieve the recommended acceptance rate, located between 0.2 and 0.45 , to find the optimal scale factor through trial and error.

Note 7. We take 100,000 Metropolis-Hastings draws to approximate the posterior density.

\section{Appendix}

According to the optimization problem of a representative household, a dynamic Lagrangian function, including 
utility function and budget constraint, can be formulated with the Lagrangian multiplier $\lambda_{t} X_{t-1}^{-\gamma}$. Then a set of efficiency conditions can be derived via the first-order condition as

$$
\begin{gathered}
{\left[C_{t} / X_{t-1}-\theta \omega^{-1} h_{t}^{\omega}\right]^{-\gamma}=\lambda_{t}} \\
{\left[C_{t} / X_{t-1}-\theta \omega^{-1} h_{t}^{\omega}\right]^{-\gamma} \theta h_{t}^{\omega-1}=(1-\alpha) a_{t}\left(\frac{K_{t}}{X_{t-1} h_{t}}\right)^{\alpha}\left(\frac{X_{t}}{X_{t-1}}\right)^{1-\alpha} \lambda_{t}} \\
\lambda_{t}=\beta \frac{1+r_{t}}{g_{t}^{\gamma}} E_{t} \lambda_{t+1} \\
{\left[1+\phi\left(\frac{K_{t+1}}{K_{t}}-g\right)\right] \lambda_{t}=\frac{\beta}{g_{t}^{\gamma}} E_{t} \lambda_{t+1}\left[1-\delta+\alpha a_{t+1}\left(\frac{X_{t+1} h_{t+1}}{K_{t+1}}\right)^{1-\alpha}+\phi\left(\frac{K_{t+2}}{K_{t+1}}\right)\left(\frac{K_{t+2}}{K_{t+1}}-g\right)-\frac{\phi}{2}\left(\frac{K_{t+2}}{K_{t+1}}-g\right)^{2}\right]}
\end{gathered}
$$

Because the model includes a trend element, $X$, we therefore detrend the above efficiency conditions to get a set of stationary equilibrium equations as

$$
\begin{gathered}
{\left[c_{t}-\theta \omega^{-1} h_{t}^{\omega}\right]^{-\gamma}=\lambda_{t}} \\
\theta h_{t}^{\omega-1}=(1-\alpha) a_{t} g_{t}^{1-\alpha}\left(\frac{k_{t}}{h_{t}}\right)^{\alpha} \\
\lambda_{t}=\frac{\beta}{g_{t}^{\gamma}}\left[1+r^{*}+\psi\left(e^{d_{t}-\bar{d}}-1\right)\right] E_{t} \lambda_{t+1} \\
{\left[1+\phi\left(\frac{k_{t+1}}{k_{t}} g_{t}-g\right)\right] \lambda_{t}=\frac{\beta}{g_{t}^{\gamma}} E_{t} \lambda_{t+1}\left[1-\delta+\alpha a_{t+1}\left(\frac{g_{t+1} h_{t+1}}{k_{t+1}}\right)^{1-\alpha}+\phi \frac{k_{t+2}}{k_{t+1}} g_{t+1}\left(\frac{k_{t+2}}{k_{t+1}} g_{t+1}-g\right)-\frac{\phi}{2}\left(\frac{k_{t+2}}{k_{t+1}} g_{t+1}-g\right)^{2}\right]} \\
\frac{d_{t+1}}{1+r_{t}} g_{t}=d_{t}-y_{t}+c_{t}+i_{t}+\frac{\phi}{2}\left(\frac{k_{t+1}}{k_{t}} g_{t}-g\right)^{2} k_{t} \\
r_{t}=r^{*}+\psi\left(e^{d_{t}-\bar{d}}-1\right) \\
k_{t+1} g_{t}=(1-\delta) k_{t}+i_{t} \\
y_{t}=a_{t} k_{t}^{\alpha}\left(g_{t} h_{t}\right)^{1-\alpha}
\end{gathered}
$$

where $c_{t}=\frac{C_{t}}{X_{t-1}}, \quad y_{t}=\frac{Y_{t}}{X_{t-1}}, \quad k_{t}=\frac{K_{t}}{X_{t-1}}, \quad d_{t}=\frac{D_{t}}{X_{t-1}}$.

The steady state values of the model variables, measured in terms of the structural parameters, can be solved as

$$
\begin{gathered}
r^{*}=\bar{g}^{-\lambda} \times \frac{1}{\beta}-1 \\
d=\bar{d} \\
\frac{k}{\bar{g} h}=\left[\left(\bar{g}^{\lambda} \times \frac{1}{\beta}-1+\delta\right) / \alpha\right]^{\frac{1}{\alpha-1}} \\
h=\left[(1-\alpha) \bar{g}\left(\frac{k}{\bar{g} h}\right)^{\alpha} / \theta\right]^{\frac{1}{\omega-1}} \\
k=\frac{k}{\bar{g} h} \times \bar{g} \times h \\
i=(\bar{g}-1+\delta) k \\
y=k^{\alpha}(\bar{g} h)^{1-\alpha}
\end{gathered}
$$




$$
\begin{aligned}
& c=\left(\frac{\bar{g}}{1+r}-1\right) \bar{d}+y-i \\
& \lambda=\left[c-\theta \omega^{-1} h^{\omega}\right]^{-\gamma}
\end{aligned}
$$

Based on the steady-state values of the model variables, we can log-linearize the model variables around their steady-state values to obtain a set of linearized equations. The linear solution technique is then applied to it to obtain the model solution for empirical analysis. In practice, we use Dynare to accomplish it.

\section{Copyrights}

Copyright for this article is retained by the author(s), with first publication rights granted to the journal.

This is an open-access article distributed under the terms and conditions of the Creative Commons Attribution license (http://creativecommons.org/licenses/by/4.0/). 